\title{
Retentivity beats prior knowledge as predictor for the acquisition and adaptation of new production processes
}

\author{
Jennifer Haase \\ Potsdam University \\ Jennifer.Haase@wi.uni-potsdam.de \\ Arnulf Schüffler \\ Ruhr-University Bochum \\ arnulf.schueffler@ruhr-uni-bochum.de
}

\author{
Julia Matthiessen \\ Potsdam University \\ Julia.Matthiessen@wi.uni-potsdam.de
}

\author{
Annette Kluge \\ Ruhr-University Bochum \\ annette.kluge@ruhr-uni-bochum.de
}

\begin{abstract}
In the time of digitalization the demand for organizational change is rising and demands ways to cope with fundamental changes on the organizational as well as individual level. As a basis, learning and forgetting mechanisms need to be understood in order to guide a change process efficiently and successfully. Our research aims to get a better understanding of individual differences and mechanisms in the change context by performing an experiment where individuals learn and later re-learn a complex production process using a simulation setting. The individual's performance, as well as retentivity and prior knowledge is assessed. Our results show that higher retentivity goes along with better learning and forgetting performances. Prior knowledge did not reveal such relation to the learning and forgetting performances. The influence of age and gender is discussed in detail.
\end{abstract}

\section{Introduction}

Increasing digitalization influences the way we work by introducing new technologies. These technologies evolve quickly leading to constant changes in working routines. Consequently, those changes in our working environment lead to adoptions in how we act in new working contexts [1]. In order to adapt efficiently, employees need to establish new working routines constantly. This requires the ability to learn new working routines and to forget old, obsolete knowledge [2]. As a main part of the Work 4.0 development includes a digital connectivity between all parts of the value chain, many changes will be experienced within all sorts of production environments [3]. In order to properly face those transformational processes of the work environment, both the organization as well as the people involved need to be equipped and prepared in a best possible way.
Research about change processes has existed for decades and has made huge steps from merely analyzing processes to a complex interaction of process, time and context [4]. Various disciplines get intertwined to analyze the complex mechanisms of change, as it includes the organizational perspective of processes and individual mechanisms of the employees [5]. Coming from this dual perspective, we like to understand how changes in working processes go along with individual markers of those people enacting the change. Learning is a basic prerequisite of the individual for any change process, and, as we will argue later, also the forgetting process. As the ability to acquire new knowledge is highly intertwined with cognitive abilities like retentivity [6] and former knowledge [7], we like to focus on the interplay of those abilities. In the present paper, we examine the role of retentivity and previous knowledge and its influence on learning and intentional forgetting in the working context using the example of a production environment.

\section{Related Literature}

\subsection{Learning}

Organizational knowledge is one of the primary success factors of a company $[8,9]$. It consists of all knowledge, skills, data and information an organization and thus its members entail [10]. Establishing new working routines requires changing organizational knowledge both by the processes of learning and forgetting [11]. Research on organizational learning began in the early 1980's and has been evolving ever since, which leads to a vast amount of definitions in this research area. Argyris and Schön [12] started by stating that organizational knowledge consists of new insights on the company level. Fiol and Lyles define organizational learning as changes in both declarative and procedural knowledge driven by experience and associations between past actions and its effect on future actions. Cumming and Whorley [13] summarize the 
debate by defining it as a change process which enables an organization to acquire new knowledge through experience. These change processes can happen on three different levels: the individual, the group and the institutional level [14]. When it comes to the underlying processes, research shows that organizational learning and the underlying memory of a company resemble an individuals' learning process [15], and that a company learns and forgets through its members [16]. Studies could show the direct relation between employees' knowledge and the overall corporate knowledge [18, 19]. Since both are related, they can influence each other in both directions: individual knowledge of employees can have a direct impact on corporate performance, e.g. in case of innovation [19], but also the company could influence an employee's memory by changing the work environment (e.g. using different memory cues [20]).

Thus, the individual learning processes play a major role in understanding organizational learning in general and one has to be accompanied by the other in order to fully understand the organizational learning process [21]. Individual learning consists of employees acquiring new knowledge and by applying it, fostering new skills, adopting new attitudes and consequently developing new competencies that are relevant for the company [14]. Taken together, organizational learning is a complex interplay between individual and institutional knowledge acquisition, skill development and the establishment of shared beliefs in order to initiate change processes [22].

\subsection{Forgetting}

While organizational learning has long been a researched field, the process of forgetting in the organizational context is increasingly coming into focus [23]. Forgetting, although often enough perceived as a malfunction and imperfection of the human brain, is actually an essential adaptive function [24]. By suppressing and arranging memory content which is not needed any more, the human brain makes it possible to handle the huge amount of information which is gathered at all times through all senses [25]. This positive approach towards forgetting is also captured under the concept of intentional forgetting. It is defined as the motivational attempt to restrict the recall of a memory item [26]. Its purposeful nature separates it quite strongly from the classical form of forgetting, which happens unintentionally and often unrecognized [27]. Especially in the context of changed working processes, intentional forgetting plays a major role since the learning of new practices alone does not guarantee the correct performance of those processes. Additionally, the old, obsolete exertions need to be forgotten in order to establish the correct performance of the new [2]. Thus, in practice, knowledge acquisition is not solely about learning, but rather an intertwined process of learning, forgetting and unlearning [28].

Individual and organizational forgetting differ most in the fact that on the individual level only one single person has to forget and on the organizational level all persons as well as all systems have to forget in order to cause a former part of organizational knowledge to be forgotten [29]. Organizations are made up of standard operating procedures and routines that organize the interplay between employees and systems [30]. Therefore, each single actor, person as well as system, is able to recall what to forget. This makes organizational forgetting much more complex than individual forgetting. Nevertheless, individual forgetting is one precondition for organizational forgetting.

\subsection{Prior knowledge}

As argued above, one key component influencing organizational competence is the process of organizational learning, both on the group as well as on the individual level [31]. Subsequent research shows that organizational learning entails different subprocesses [32], namely knowledge acquisition, knowledge distribution, interpretation and organizational memory. For the latter, the process of forgetting and intentional forgetting can be subordinated. Intraindividual factors can potentially influence these subprocesses, thus influencing learning and intentional forgetting in organizations [33].

One of these influencing factors is the individual level of prior knowledge. We can remember new information better when it relates to knowledge structures we already have memorized [34]. Ausubel ascribed this as the most important single factor for learning: what the learner already knows [35]. Prior knowledge entails all knowledge (as acquisition of information) and skills (as application of knowledge) of a person in a particular domain including knowledge assets connected through close links, which build a functional unit [36]. In turn, these units can be used in an integrated way when dealing with domain-specific problems [37]. Research in various fields succeeded in supporting this hypothesis $[39,40,41]$. The underlying reason is supposed to be that the increase in taskrelevant knowledge facilitates the formation of new associations in the hippocampus which is accompanied by increased communication between the hippocampus and semantic process areas [36]. In order to use prior knowledge, it has to be activated by retrieving stored information from the long-term memory and keeping this information available in the working memory [41].

The role of prior knowledge in the organizational learning and forgetting context is not fully examined. It 
can be argued that the benefits of individual prior knowledge have positive effects on the above mentioned subprocesses of organizational learning, namely knowledge acquisition and knowledge interpretation, as employees have more knowledge at hand to interpret and understand organizational change processes. Additionally, research shows that training employees, which can be considered to be one way of generating prior knowledge, has positive effects on job performance $[43,44]$, which in turn can be perceived as an improvement for the process of organizational learning. To our knowledge, the influence of prior knowledge on intentional forgetting in the working context has not yet been examined.

\subsection{Retentivity}

Investigating the interplay of learning and forgetting in mastering the change of a production process, retentivity describes the individual ability to memorize and reproduce information and associations that were learned a short time ago. It is the ability to store and recall information in the short and medium term $[45,46$, 47].

Retentivity is a facet of fluid intelligence based on the modified model of primary mental abilities [46] from Spearman's concept of intelligence [48]. Retentivity as primary mental ability consists of three content abilities: verbal (e.g. communication skills), numerical (e.g. mathematical skills) and figural memorization (e.g. spatial skills). Studies could prove that all three facets affect work performance and learning-performance in general $[49,50,51,52]$.

When it comes to the organizational context, one study picks up on the idea of seeing retentivity as an influencing component in the learning process. Lytras, Pouloudi and Poulymenaku [53] succeeded in showing that retentivity in the work context affects learning significantly. If the recipient lacks retentive capacity or motivation, knowledge transfer is impaired.

Otherwise, retentivity in the organizational learning context has been studied solely by focusing on the skill level [50], thus taking a more practically oriented perspective. Again, research has been conducted to show that skill retention is influenced by a vast number of factors, e.g. overtraining or the retention interval [54]. It is arguable that similar factors might apply to retentivity of theoretical information in a company. Interestingly, Kluge and Frank [55] were able to show that the opposite process, namely skill decay, is not equivalent to knowledge decay in the underlying procedure. To be precise, knowledge decay appears to manifest less strongly than skill decay. Thus, it remains unclear whether the same processes influence knowledge retentivity and skill retention.
Focusing on the relationship between forgetting and retentivity, it seems intuitive to consider them as two contrasting constructs, as high retentivity can be suggested to hinder the process of forgetting. MacLeod [56] conducted two experiments that support that intuition. He examined long-term retentivity measures in a sample of undergraduate students that received instructions of either remembering or forgetting given categories. In the first experiment, recognition and cued recall measures were better for categories that were attached to the remember instructions. The second experiment included two subsequent weeks as retention interval. Again, categories of the remember instruction were superior than categories of the forgetting instruction. Thus, the study seems to support the idea that the directed forgetting effect affects retentivity over time. In another study, researchers were able to demonstrate that directed forgetting works early on in life and that its influence on retentivity is more complex [57]. Pre- schoolers were asked to learn a list of everyday objects and then either forget or remember that list. Afterwards, they had to learn another unrelated list of words. Results show that children in the forgetting condition had difficulties in remembering the first list, whereas they demonstrated increased retention rates for the second list. Consequently, directed forgetting might reduce a person's retentivity for irrelevant information, but facilitates learning of new information in turn. Having this in mind, retentivity and forgetting seem to be more related than expected. Again, the construct of retentivity is seen as a consequence of (intentional) forgetting, not as an influencing component. More research is needed to find out whether these relationships can also be applied to the work context, especially in the work context of a changing situation.

\subsection{Demographical change}

A topic to keep in mind is the influence of age on the cognitive processes of learning and forgetting. The demographic change is omnipresent, also in the work 4.0 context. According to European and American studies, the proportion of older employees in these countries is constantly rising $[58,59,60]$. Studies show that age influences the learning process in manifold ways. In general, cognitive memory processes decline with age, especially with regards to the episodic memory [61, 62]. Tasks such as list recall [62] or item recognition [63], which are associated with the functioning of episodic memory, have been found to underlie age effects. Although the phenomenon is manifold, the most common underlying reasons in the case of a healthy brain are the age-related deterioration of brain structures due to the weakening of neural circuits as well as the decrease of white matter 
especially in memory-related areas such as the prefrontal cortex and the hippocampus [64]. Salthouse [62] found that this general cognitive decline starts early in adulthood, between 20 and 30 years of life, but not all aspects of cognitive functioning are equally concerned. Following an analysis based on 5,391 participants, memory, in particular, decreases constantly with age, starting from the early twenties [65]. By means of a conclusive literature review, Umanath and Marsh [66] found that prior knowledge can have a positive impact on older people's learning behavior by potentially compensating for age-related cognitive decline in memory [67]. Specifically, literature shows that prior knowledge is most helpful for environments in which a person's expectation matches the information that needs to be remembered [68].

When it comes to the organizational context, the picture is inconsistent. Whereas some studies argue that older employees, with "old" not being specified further, perform worse due to cognitive and physical decline [69], other studies argue that no difference in age groups can be found [70, 71]. Experienced based knowledge was found to be an advantage for older employees in dealing with complex work problems [72].

Murphy [73] argues that the relationship between cognitive processes and job performance depends on the situation. Accordingly, age-related cognitive decline can act out on transitional situations in which employees need to acquire new knowledge, whereas the decline is less impactful in situations of maintenance and job stability. It is arguable that older employees have gathered experienced based knowledge over their lifespan, which can be seen as a form of prior knowledge. This, in turn, might compensate for age related learning deficits in the context of work when it comes to learning content that is related to existing knowledge.

\subsection{Research questions}

As outlined above, prior knowledge works as a foundation and anchor for new information to be learned. Thus, we propose that the more prior knowledge a person contains about a production work setting, the more accurate the acquisition and performance of the production process will be (Hypothesis 1). In addition to that, the acquisition of new knowledge in a short time relies on the person's retentivity level. Thus, we propose that the higher the retentivity, the more accurate the acquisition and performance of the production processes (Hypothesis 2). This also includes intentional forgetting, as it requires remembering partly contradicting informa-tion to the already acquired information which was learned a short time before.
Since older employees (above 30 years) potentially entail more prior knowledge which can compensate for cognitive decline, we don't expect an age effect in learning (Hypothesis 3). Additionally, since retentivity rates decline with age, starting in the early twenties [66] those actions which need to be relearned quickly (intentional forgetting) should decrease for older participants, which could be expressed twofold: by worse performance and by slower performance (Hypothesis 4).

\section{Experimental design}

The experiment took place at the Research and Application Center for Industry 4.0 (RACI) at the University of Potsdam, Germany. From January until August 2018, 41 participants, which were mostly students, took part in the study. They were all acquired via social media and university lectures. As a compensation, they got $40 €$ for the completion of the whole experiment. The participants were $58,5 \%$ male, with a mean-age of 26.63 years $(\mathrm{SD}=7.63$, range from 20 to 61 years). No one had experience with the experimental setting.

\subsection{The experimental environment}

In order to assess forms of forgetting, participants first had to build up some knowledge which could then be instructed to be forgotten. Thus we created an experimental design with two laboratory sessions and a delay of three weeks in which the participants consolidated the learned information from the first session using an online application. The RACI provides a hybrid production simulation with hardware and software components from real production settings [74]. It can be used to mimic a realistic factory environment, which still can be controlled to serve an experimental purpose. Participants can interact with the hardware components like machine interfaces, robots, scanner and computer. Fitting visual and audible stimuli are also presented, with the aim to enhance the participants immersion [74]. In the experiment, the simulation case of a knee joint production is presented, which stems from a real production setting, with original photo and audio footage. This scenario was chosen because the enforcement of a rigid production procedure is plausible in the context of high quality standards for a medical product. Plus, we assumed this specific knowledge about knee implants is new for every participant.

In the production process, the knee joint undergoes the whole manufacturing chain from the blank in the warehouse to the finished product being packed. Three workers are included, working on three separate working stations. The workpiece is represented as a "cube" which moves over an assembly line (compare 


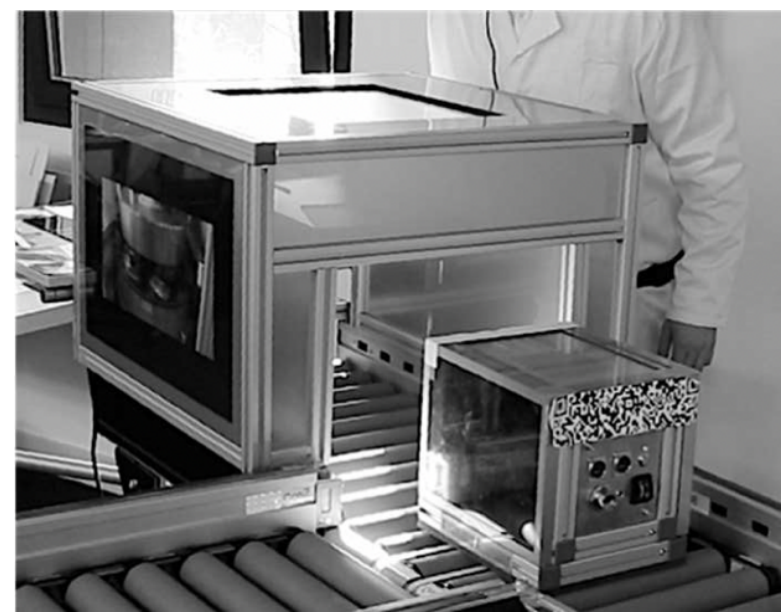

Figure 1. Big cube with station: Machine for worker 1. Small cube: work piece on the assembly line

small cube in Figure 1), passing all three working stations (compare big cube in Figure 1). For the first station, the blank is taken from the warehouse and put on the assembly line. The worker measures its size, miles and grinds it. It is then sent to the next working station where the second worker uses a robot to laser and polish the working piece. At the third working station, the piece is checked for quality standards, sterilized and packed for transportation. Each working station consists of a big cube representing the machine with a touch-screen as a machine interface. Those are attached to the assembly line, so the work piece can be located inside the machine. For worker two, the machine-cube is used to control the robot which lasers and polishes the work piece at the assembly line. The whole production process is enriched by the use of diverse materials, like a scanner, caliper, diverse polisher, cardboard and diverse paperwork. The three working stations entail specific actions for the participants, so they become experts in their specific role. There are also actions which are the same for all three workers that concern the registration of each new work piece at the production data acquisition (PDA) station.

\subsection{The experimental setup}

For each experimental run, a group of three participants come to the laboratory and are assigned to a working position by chance. They acquire the specific production routine with the help of a manual and guidance from the investigator whenever needed. The first three working pieces are for practice, followed by a 40-minute free production phase, where the team is supposed to produce as many correct pieces as possible. After the first laboratory session (t1), all workers practice the working routine at home using an online app which mimics the laboratory setting. They are instructed to use the app at the $7^{\text {th }}$ and $14^{\text {th }}$ day after the first session for about 30 minutes each. At the $21^{\text {st }}$ day they again come to the laboratory once again ( $\mathrm{t} 2)$ with the expectation to repeat the routine they had learned the last time. However, we explain that due to a fusion of the company where the production process comes from, certain features of the process had to be adapted and thus have to be done differently in the subsequent session. Again, with the help of a manual they learn about the changes and get one working piece to practice. After that, again they are supposed to produce as many correct pieces as possible within 40 minutes.

\subsection{Data acquisition}

At the beginning and end of each laboratory session, questionnaires were used to collect personal data as control variables. Besides general sociodemographic data, several scales about general and specific selfefficacy, immersion, subjective switching costs, previous knowledge (PK), and retentivity (Ret.) were assessed. Only the latter two are important in the context of this paper. The part of PK contains eleven questions with content relevant to the production context of the experiment (scale was self-constructed, e.g. "What is a QR-Code?", "What means sterilization?") and was assessed right at the beginning of $\mathrm{t} 1$. For each question, four possible answers were presented, where one to four could be correct. The higher the score of a participant, the better his/her knowledge of general manufacturing settings. Retentivity was assessed at the end of $\mathrm{t} 2$ using the retentivity-subscale of the Wilde-Intelligenz-Test-2 (Wilde intelligence test - 2, [46]).

Concerning the performance of the production process, there were three different sources of data from the experiment. First, logfiles from direct interaction with computer interfaces on the machines and the PDAterminal. Second, the participants were wearing eyetrackers so their activities could be tracked and added to the data set. Third, the production process is accompanied by various paperwork where the participants had to write down and highlight certain information. In total, taking all three workers together, 99 action elements are assessed for each work piece they produce. From those, 45 are of interest when looking at individual forgetting-performance, since those include the changes from t 1 to $\mathrm{t} 2$ (for a more detailed explanation of the experimental setting see [20]).

For each worker there is one precisely defined correct routine for $\mathrm{t} 1$ and $\mathrm{t} 2$, respectively. Thus, the data from all three sources is judged as either correct or false for each specific action, dependent on whether the participant performed the actions as the routine of $\mathrm{t} 1$ or t2 demands it. Furthermore, a Neutral category is 
assigned in case an action cannot be clearly evaluated as either correct or wrong, as some elements are imprecise, which is then treated as missing data.

The performance at $\mathrm{t} 1$ is taken as a measure for learning, resulting in an overall correct (Correct t1) vs. false (False t1) performance score. Performance scores for $\mathrm{t} 2$ are comprised of several sub-scores, as the new routine includes different changes in regard to the $\mathrm{t} 1$ process: insertions (new actions at $\mathrm{t} 2$ ), omissions (actions were present at $\mathrm{t} 1$ but deleted at $\mathrm{t} 2$ ) and changes (action was present at $\mathrm{t} 1$ and is changed at $\mathrm{t} 2$ ). For the last two, a process of intentional forgetting is assumed, as these require the participants to suppress the original routine from $\mathrm{t} 1$ for the sake of the newly learned routine. The overall correct vs. false performance at $\mathrm{t} 2$ is again combined to an overall score (Correct t2, False t2), with errors concerning intentional forgetting as a separate score (False IF).

\section{Analysis section}

In order to test the hypotheses, means and standard deviations are computed for all performance scores, as well as in dependence of prior knowledge and retentivity (compare Table 1). PK reached a mean of .70 $(\mathrm{SD}=.14$, range of .42 to .92$)$ and Ret. reached a mean of $.34(\mathrm{SD}=.14$, range of .19 to .86$)$.

Hypothesis 1 stated a positive relation between PK and learning performances. The overall correct actions at t1 show the proposed relation with a Pearsoncorrelation for PK of: $r(39)=.32, p=.048$. However, when the participants with high scores for PK are compared to those with lower scores, no differences for the means of the learning performance measures emerge (compare Table 1).

Addressing hypothesis 2, a positive relationship between retentivity, learning and intentional forgetting measures was proposed, which could partly be found: retentivity shows a Pearson-correlation with Correct t1 of $r(39)=.35, p=.027$, and with a sub-score of False t 2 (failures to perform new actions at $\mathrm{t} 2$ ) $r(39)=-.32, p=$

Table 1

Means (standard deviations) of the performance scores with a division for high and low performer as well as the ten oldest vs. ten youngest participants, with significance testing (one-sided) for the subsamples.

\begin{tabular}{|c|c|c|c|c|c|c|c|}
\hline & $\mathrm{N}$ & $\mathrm{m}$ & $\begin{array}{c}\text { Correct } \\
\mathrm{t} 1\end{array}$ & $\begin{array}{c}\text { False } \\
\mathrm{t} 1\end{array}$ & $\begin{array}{c}\text { Correct } \\
\mathrm{t} 2\end{array}$ & $\begin{array}{c}\text { False } \\
\mathrm{t} 2\end{array}$ & $\begin{array}{c}\text { False } \\
\text { IF }\end{array}$ \\
\hline Overall & 41 & & $\begin{array}{l}.71 \\
(.11)\end{array}$ & $\begin{array}{l}.37 \\
(.62)\end{array}$ & $\begin{array}{l}.71 \\
(.12)\end{array}$ & $\begin{array}{l}.30 \\
(.13)\end{array}$ & $\begin{array}{l}.07 \\
(.06)\end{array}$ \\
\hline better PK & 20 & $\begin{array}{l}.81 \\
(.07)\end{array}$ & $\begin{array}{l}.74 \\
(.08)\end{array}$ & $\begin{array}{c}.27 \\
(.12)\end{array}$ & $\begin{array}{l}.73 \\
(.10)\end{array}$ & $\begin{array}{l}.29 \\
(.11)\end{array}$ & $\begin{array}{l}.07 \\
(.06)\end{array}$ \\
\hline worse PK & 20 & $\begin{array}{l}.58 \\
(.09)\end{array}$ & $\begin{array}{l}.69 \\
(.12)\end{array}$ & $\begin{array}{c}.48 \\
(.88)\end{array}$ & $\begin{array}{l}.71 \\
(.13)\end{array}$ & $\begin{array}{l}.32 \\
(.15)\end{array}$ & $\begin{array}{l}.07 \\
(.07)\end{array}$ \\
\hline $\begin{array}{l}t(\mathrm{DF}=38) \\
(p)\end{array}$ & & $\begin{array}{c}-9.02 \\
(<.0001)\end{array}$ & $\begin{array}{l}-1.55 \\
(.07)\end{array}$ & $\begin{array}{l}1.06 \\
(.15)\end{array}$ & $\begin{array}{l}-.55 \\
(.30)\end{array}$ & $\begin{array}{l}.72 \\
(.24)\end{array}$ & $\begin{array}{l}0.00 \\
(.50)\end{array}$ \\
\hline better Ret. & 22 & $\begin{array}{l}.73 \\
(.05)\end{array}$ & $\begin{array}{l}.75 \\
(.10)\end{array}$ & $\begin{array}{c}.41 \\
(.85)\end{array}$ & $\begin{array}{c}.74 \\
(.10)\end{array}$ & $\begin{array}{l}.26 \\
(.10)\end{array}$ & $\begin{array}{l}.05 \\
(.04)\end{array}$ \\
\hline worse Ret. & 18 & $\begin{array}{l}.51 \\
(.13)\end{array}$ & $\begin{array}{l}.66 \\
(.10)\end{array}$ & $\begin{array}{l}.31 \\
(.14)\end{array}$ & $\begin{array}{c}.69 \\
(.13)\end{array}$ & $\begin{array}{l}.35 \\
(.13)\end{array}$ & $\begin{array}{l}.09 \\
.08)\end{array}$ \\
\hline $\begin{array}{l}t(\mathrm{DF}=38) \\
(p)\end{array}$ & & $\begin{array}{c}-7.32 \\
(<.0001)\end{array}$ & $\begin{array}{l}-2.70 \\
(.005)\end{array}$ & $\begin{array}{l}-.52 \\
(.30)\end{array}$ & $\begin{array}{l}-1.50 \\
(.07)\end{array}$ & $\begin{array}{l}2.41 \\
(.01)\end{array}$ & $\begin{array}{l}1.98 \\
(.03)\end{array}$ \\
\hline $\begin{array}{l}\text { Youngest } \\
(20-22 y)\end{array}$ & 10 & $\begin{array}{c}21.00 \\
(.82)\end{array}$ & $\begin{array}{c}.69 \\
(.07)\end{array}$ & $\begin{array}{c}.34 \\
(.11)\end{array}$ & $\begin{array}{c}.72 \\
(.11)\end{array}$ & $\begin{array}{c}.33 \\
(.12)\end{array}$ & $\begin{array}{c}.06 \\
(.08)\end{array}$ \\
\hline $\begin{array}{l}\text { Oldest } \\
\text { (30-61y) }\end{array}$ & 10 & $\begin{array}{l}36.40 \\
(9.94)\end{array}$ & $\begin{array}{c}.69 \\
(.14)\end{array}$ & $\begin{array}{c}.70 \\
(1.23)\end{array}$ & $\begin{array}{l}.66 \\
(.18)\end{array}$ & $\begin{array}{l}.30 \\
(.16)\end{array}$ & $\begin{array}{l}.10 \\
(.08)\end{array}$ \\
\hline$t(\mathrm{DF}=18)$ & & $\begin{array}{c}4.88 \\
(<.0001)\end{array}$ & $\begin{array}{l}0.00 \\
(50)\end{array}$ & $\begin{array}{l}.92 \\
(.18)\end{array}$ & $\begin{array}{l}-.90 \\
(.19)\end{array}$ & $\begin{array}{l}-.47 \\
(.32)\end{array}$ & $\begin{array}{l}1.12 \\
(14)\end{array}$ \\
\hline
\end{tabular}

Notes: $\mathrm{PK}=$ prior knowledge, Ret. $=$ retentivity, correct $=$ overall score for all correctly performed actions at $\mathrm{t} 1$ and $\mathrm{t} 2$, false $=$ overall score for all falsely performed actions at $\mathrm{t} 1$ and $\mathrm{t} 2$, False IF = overall score for falsely performed actions which required intentional forgetting, $\mathrm{DF}=$ Degree of freedom for $t$-Test (one-sided). 
.04. Participants with higher scores in retentivity have significantly more correct performances at $\mathrm{tl}(t(38)=$ $2.70, p=.005)$, and significantly less failures in $\mathrm{t} 2(t(38)$ $=2.41, p=.01)$ compared to those with lower scores. Further, participants with higher retentivity scores make significantly less intentional forgetting failures.

For hypothesis 3, it was stated that older employees potentially entail more prior knowledge which can compensate for cognitive declines, which would lead to no age differences in learning. However, no superiority of prior knowledge for older participants could be found. Further, only the ten oldest participants showed a significant high Pearson-correlation with Correct t1 performance with PK $(r(18)=.67, p=.048)$ and Ret. $(r(18)=.83, p=.006)$.

As retentivity slows down with age, the learning and intentional forgetting performance of those processes that have to be learned fast should be worse for older participants (Hypothesis 4). As it can be seen in Table 1, older participants do not perform worse compared to the younger ones. However, older participants are slower: at $\mathrm{t} 1$, the overall time for the whole process is significantly longer compared to younger participants $\left(m_{\text {oldest }}=5376.40 \mathrm{sec}, \quad \mathrm{SD}_{\text {oldest }}=528.75 \mathrm{sec} . \quad\right.$ vs. $\mathrm{m}_{\text {youngest }}=4988.70 \mathrm{sec} ., \quad \mathrm{SD}_{\text {youngest }}=248.82 \mathrm{sec}$. $t(18)=2.09, p=.05)$. This does not hold for $t 2$, as older participants are as fast as younger ones $\left(m_{\text {oldest }}=3783.20 \mathrm{sec}, \quad \mathrm{SD}_{\text {oldest }}=971.61 \mathrm{sec} . \quad\right.$ vs . $m_{\text {youngest }}=3728.52$ sec., $\quad \mathrm{SD}_{\text {youngest }}=750.82 \mathrm{sec}$. $t(18)=.10, p=.92)$.

When checking for gender as a moderator a pattern emerged, as the relation between retentivity and the performance at $\mathrm{t} 1$ is only significant for women (Correct t1: $r(16)=.52, p=.039$; False t1: $r(16)=-.652, p=$ .006). In line with that, sub-scores about the performance at $\mathrm{t} 2$ only show high correlation with retentivity for women (correctly performed changed actions at $\mathrm{t} 2: r(16)=.54, p=.031$, correctly performed new actions at $\mathrm{t} 2: r(16)=.73, p=.001$; falsely performed new actions at $\mathrm{t} 2: r(16)=-.82, p=.0001$, correctly not performing deleted actions from $\mathrm{t} 1$ at $\mathrm{t} 2$ : $r(16)=.59, p=.017)$. All those performance measures correlate close to zero for men and are non-significant.

\section{Discussion}

The purpose of the study was to investigate the relation between prior knowledge, retentivity and the performance at a new and later changed production process in the most realistic and practical fashion. Whereas most experimental studies examined memory related performances in more abstract ways, through list learning and different recall strategies, we aimed to investigate the complex pattern of learning and forgetting with a simulation of a real-world scenario of a production process. The relations found are partly in line with the literature, but do not always present a clear pattern of the relations between those constructs. The rapid acquisition of a new and complex production process is essentially supported by the level of retentiveness a person holds. Participants with higher retentivity scores perform more correct actions during the first experimental session and also make fewer mistakes when the process is changed at the second session. This might indicate a certain competence to rapidly adapt to new actions, which participants with lower retentivity scores did not show.

Concerning the specific intentional forgetting measures, participants with higher retentivity were better at performing actions which demanded intentional forgetting, compared to those with lower scores. Thus, our study manifests retentivity as beneficial for short term learning and adaptation of already established knowledge.

However, this effect could not be found for all performance scores, so the results need to be interpreted with caution. The results based on age show a clearly slower performance for older participants when the production process was totally new at the first session. This speed-difference was made up at the second session, as no age-effects could be found. Also, for the different performance measures, no age-effect was of significance. A limiting factor might be the agedistribution of our sample as it is limited for older participants. This makes the age-distribution for the oldest 10 much broader compared to the 10 youngest. However, missing significant differences on the performance scores based on age-differences could also be a result of a more realistic research design. As most classical designs for assessing learning and forgetting include the usage of often quite rigid methods, like list learning and rehearsing, participants are prevented from using natural compensatory strategies. Our design allows for such compensation, which might explain our results.

Similarly, to the age effects, no performance differences could be found based on gender. However, an interesting and persistent pattern emerged where women seem to rely much more on their retentivity, as higher scores go along with an overall better performance (higher correct and lower failure scores). As men did not show anything close to this pattern, their performance appears to be unrelated to retentivity and must rely on factors we did not assess.

We see a great advantage in our rather complex experimental design especially in the sense of ecological validity, as we aimed for the most realistic production setting [75]. To our knowledge, there are no similar complex designs in the context of production 
process simulations available to compare our study with. Usually, when analyzing learning and forgetting, simpler and, for the sake of controllability, more artificial designs are used [76]. The implications from this study can be better assigned to real-world change processes in production settings, where learning and forgetting is involved. For example, students got paid for the experiment, which worked as a motivator similar to a working environment. It is still limited in terms of generalizability, as not all aspects of an organization were mimicked in our production setup, and the production process, though complex for an experiment, was still modest for a real production. The students in the study might not be representative of production workers, especially concerning education and age. In general, students seem to be different compared to the general public, as they differ in many personality scores, attitudes and general cognitive abilities (compare [77, 78]). However, we argue that the usage of a student sample benefits the aim of studying learning and forgetting in a production setting. When studying forgetting, the content that should be forgotten needs to be controlled precisely. As those students demonstrated only marginal previous experiences in such working environments, controllable study conditions are present.

Another limitation arises as scores were used to limit the complexity. The performance is composed of a great quantity of individual actions which were performed repeatedly and then aggregated to scores. However, this might cover up specifics in the individual's performance, which are not analyzed in more detail at the moment, like focusing on learning and forgetting curves developing with each single applied production process.

Overall, our study provides first ideas on how retentivity and prior knowledge are generally related to learning and forgetting of working routines, which is especially important in the context of organizational change and the frequent technical innovations in a digital age [3]. Thus, it adds to a corpus of studies that aim to evaluate paths to cope with frequent change in the workplace.

As a next step, the mode of action for intentional forgetting in routines will be analyzed in a group setting. Most production processes take place in highly dynamic and socially interactive settings, thus creating the need to further understand intentional forgetting on team and organizational levels.

Future studies should look more deeply into the relation of retentivity and learning and forgetting, especially to define age differences more precisely. A similar study with real production workers is needed in order to fully understand the individually different working mechanisms for learning and forgetting for those participants who would actually be affected by such routine changes.

\section{Acknowledgement}

The project is partly funded from 2016-2019 by the Deutsche Forschungsgemeinschaft (DFG), project numbers KL2207/6-1 and GR 1846/21-1.7, as well as the Federal Ministry of Education and Research of Germany (BMBF) under grant no. 16DII116 ("Deutsches Internet-Institut").

\section{References}

[1] G. P. Huber, "Organizations: theory, design, future," APA Handb. Ind. Organ. Psychol. Dev. Organ., vol. 1, pp. 117-160, 2011.

[2] A. Kluge and N. Gronau, "Intentional Forgetting in Organizations: The Importance of Eliminating Retrieval Cues for Implementing New Routines," Front. Psychol., vol. 9, 2018.

[3] C. Fischer and A. Pöhler, "Supporting the Change to Digitalized Production Environments Through Learning Organization Development," in The Impact of Digitalization in the Workplace: An Educational View, C. Harteis, Ed. Cham: Springer International Publishing, 2018, pp. 141-160.

[4] A. M. Pettigrew, R. W. Woodman, and K. S. Cameron, "Studying organizational change and development: Challenges for future research," Acad. Manage. J., vol. 44, no. 4, pp. 697-713, 2001.

[5] D. Collins, Organisational Change : Sociological Perspectives. Routledge, 2005.

[6] A. Kluge, B. Frank, S. Maafi, and A. Kuzmanovska, "Does skill retention benefit from retentivity and symbolic rehearsal? - two studies with a simulated process control task," Ergonomics, vol. 59, no. 5, pp. 641-656, May 2016.

[7] Y. Engeström, Learning by expanding. Cambridge University Press, 2014.

[8] H. Tsoukas and E. Vladimirou, "What is Organizational Knowledge?,” J. Manag. Stud., vol. 38, no. 7, pp. 973-993, Nov. 2001.

[9] G. Cepeda-Carrion, J. Cegarra, and E. Martínez-Caro, Improving the absorptive capacity through unlearning context: An empirical investigation in hospital-in-thehome units, vol. 32. 2012.

[10] I. Nonaka and H. Takeuchi, The Knowledge-Creating Company - How Japanese Companies Create the Dynamics of Innovation. New York: Oxford University Press, 1995.

[11] E. W. K. Tsang and S. A. Zahra, "Organizational unlearning," Hum. Relat., vol. 61, no. 10, pp. 14351462, 2008.

[12] C. Argyris and D. A. Schön, A theory of action perspective. Addison-Wesley Publishing Company, 1978.

[13] T. G. Cummings and C. G. Worley, Organization Development and Change. South-Western/Cengage Learning, 2009.

[14] J. M. Namada, "Organizational learning and competitive advantage," in Handbook of Research on 
Knowledge Management for Contemporary Business Environments, IGI Global, 2018, pp. 86-104.

[15] J. P. Walsh and G. R. Ungson, "Organizational memory,” Acad. Manage. Rev., vol. 16, no. 1, pp. 5791, 1991.

[16] B. Hedberg, Handbook of Organizational Design: "how Organizations Learn and Unlearn." Arbetslivscentrum, 1981.

[17] A. Kianto, J. Sáenz, and N. Aramburu, "Knowledgebased human resource management practices, intellectual capital and innovation," J. Bus. Res., vol. 81, pp. 11-20, 2017.

[18] J. Brennecke and O. Rank, "The firm's knowledge network and the transfer of advice among corporate inventors-A multilevel network study," Res. Policy, vol. 46, no. 4, pp. 768-783, 2017.

[19] S.-Y. Ahn and S.-H. Kim, "What makes firms innovative? The role of social capital in corporate innovation," Sustainability, vol. 9, no. 9, p. 1564, 2017.

[20] J. Haase and A. Schüffler, "Studying cue-dependent and intentional forgetting in organizations: a methodological approach," presented at the Hawaii International Conference on System Sciences, 2019.

[21] C. Thim, N. Gronau, and A. Kluge, "Managing Change Through a Work Environment Which Promotes Forgetting," presented at the Hawaii International Conference on System Sciences, 2019.

[22] L. Argote, "Organization learning: A theoretical framework," in Organizational learning, Springer, 2013, pp. 31-56.

[23] T. Ellwart et al., "Intentional Forgetting in SocioDigital Work Systems," AIS Trans. Enterp. Syst., vol. 4, no. 1, 2019.

[24] R. A. Bjork, "Intentional Forgetting in Perspective: Comments, Conjectures, and Some Directed Remembering," in Intentional Forgetting: Interdisciplinary Approaches, J. M. G. \& C. M. MacLeod, Ed. Mahwah, NJ: Lawrence Erlbaum, 1998, pp. 453-481.

[25] H. Roedinger, Y. Weinstein, and P. K. Agarwal, "Forgetting: preliminary considerations," in Forgetting, Psychology Press, 2010, pp. 15-36.

[26] E. L. Bjork, R. A. Bjork, and M. C. Anderson, "Varieties of goal-directed forgetting," in Intentional Forgetting: Interdisciplinary Approaches, J. M. Golding and C. M. MacLeod, Eds. Mahwah, NJ: Lawrence Erlbaum, 1998, pp. 103-137.

[27] R. G. Crowder, Principles of Learning and Memory, 1 edition. Psychology Press, 1976.

[28] M. Visser, "(6) Learning and unlearning: a conceptual note," ResearchGate. [Online]. Available: https://www.researchgate.net/publication/313682986_ Learning_and_unlearning_a_conceptual_note. [Accessed: 08-Aug-2018].

[29] Schüffler, A., Thim, C., Haase, J., Gronau, N., \& Kluge, A. (2019). ,Willentliches Vergessen Voraussetzung für Flexibilität und Veränderungsfähigkeit in einer sich permanent verändernden Welt,“ Gruppe. Interaktion. Organisation. Zeitschrift Für Angewandte
Organisationspsychologie (GIO), 50(2), pp. 197-209.

[30] Becker, M. C. (2004). "Organizational routines: a review of the literature," Industrial and corporate change, 13(4), pp. 643-678.

[31] K. M. Eisenhardt and J. A. Martin, "Dynamic capabilities: what are they?," Strateg. Manag. J., vol. 21, no. 10-11, pp. 1105-1121, 2000.

[32] P. Weerd-Nederhof, B. J. Pacitti, J. Gomes, and A. W. Pearson, “Tools for Improvement of Organizational Learning Processes in Innovation," J. Workplace Learn., vol. 14, pp. 320-331, 2002.

[33] D. Jiménez-Jiménez and R. Sanz-Valle, "Innovation, organizational learning, and performance," J. Bus. Res., vol. 64, no. 4, pp. 408-417, 2011.

[34] M. T. R. van Kesteren, M. Rijpkema, D. J. Ruiter, R. G. M. Morris, and G. Fernández, "Building on Prior Knowledge: Schema-dependent Encoding Processes Relate to Academic Performance,” J. Cogn. Neurosci., vol. 26, no. 10, pp. 2250-2261, 2014.

[35] D. P. Ausubel, The acquisition and retention of knowledge: A cognitive view. Springer Science \& Business Media, 2012.

[36] G. Brod, U. Lindenberger, A. D. Wagner, and Y. L. Shing, "Knowledge Acquisition during Exam Preparation Improves Memory and Modulates Memory Formation,” J. Neurosci., vol. 36, no. 31, pp. 81038111, Aug. 2016.

[37] A. Renkl, "Lehren und Lernen," in Handbuch Bildungsforschung, Springer, 2010, pp. 737-751.

[38] J. Möller, Emotionen, Kognitionen und Schulleistung. Beltz, Psychologie-Verlag-Union, 1996.

[39] R. Stark, "Conceptual change: From a cognitive or situated perspective?," Z. Pädagogische Psychol., vol. 17, no. 2, pp. 133-144, 2003.

[40] G. Roth, "Warum sind Lehren und Lernen so schwierig?," Z. Für Pädagog., vol. 50, no. 4, pp. 496506, 2004.

[41] A. Baddeley, "Working memory: looking back and looking forward," Nat. Rev. Neurosci., vol. 4, no. 10, pp. 829-839, Oct. 2003.

[42] A. Elnaga and A. Imran, "The effect of training on employee performance,” Eur. J. Bus. Manag., vol. 5, no. 4, pp. 137-147, 2013.

[43] M. E. Beier and P. L. Ackerman, "Age, Ability, and the Role of Prior Knowledge on the Acquisition of New Domain Knowledge: Promising Results in a RealWorld Learning Environment.," Psychol. Aging, vol. 20, no. 2, pp. 341-355, 2005.

[44] A. O. Jäger, H.-M. Sü\s s, and A. Beauducel, Berliner Intelligenzstruktur-Test: BIS-Test. Hogrefe, 1997.

[45] L. L. Thurstone, Primary mental abilities. Chicago: Univer. of Chicago Press, 1938.

[46] M. Kersting, K. Althoff, and A. O. Jäger, WildeIntelligenz-Test 2: WIT-2. Hogrefe, Verlag für Psychologie, 2008.

[47] J. Kramer, "Allgemeine Intelligenz und beruflicher Erfolg in Deutschland: vertiefende und weiterführende Metaanalysen," Psychol. Rundsch., vol. 60, no. 2, pp. 82-98, 2009. 
[48] C. Spearman, ““ General Intelligence,' objectively determined and measured," The American Journal of Psychology, vol. 15, no. 2, pp. 201-292, 1904.

[49] D. S. Ones, S. Dilchert, and C. Viswesvaran, "10 Cognitive Abilities,” Oxf. Handb. Pers. Assess. Sel., p. 179, 2012.

[50] N. Schmitt, "Personality and cognitive ability as predictors of effective performance at work," Annu Rev Organ Psychol Organ Behav, vol. 1, no. 1, pp. 4565, 2014.

[51] J. W. Lang, M. Kersting, U. R. Hülsheger, and J. Lang, "General mental ability, narrower cognitive abilities, and job performance: The perspective of the nestedfactors model of cognitive abilities," Pers. Psychol., vol. 63, no. 3, pp. 595-640, 2010.

[52] N. Linou and T. Kontogiannis, "The Effect of Training Systemic Information on the Retention of FaultFinding Skills in Manufacturing Industries.," Hum. Factors Ergon. Manuf., vol. 14, no. 2, pp. 197-217, 2004.

[53] M. D. Lytras, A. Pouloudi, and A. Poulymenakou, "Knowledge management convergence-expanding learning frontiers," J. Knowl. Manag., vol. 6, no. 1, pp. 40-51, 2002.

[54] G. Matthews, D. R. Davies, R. B. Stammers, and S. J. Westerman, Human performance: Cognition, stress, and individual differences. Psychology Press, 2000.

[55] A. Kluge and B. Frank, "Counteracting skill decay: four refresher interventions and their effect on skill and knowledge retention in a simulated process control task," Ergonomics, vol. 57, no. 2, pp. 175-190, 2014.

[56] C. M. MacLeod, "Long-term recognition and recall following directed forgetting.," J. Exp. Psychol. [Hum. Learn.], vol. 1, no. 3, p. 271, 1975.

[57] A. Hupbach, "Long-term effects of directed forgetting," Memory, vol. 26, pp. 1-9, 2017.

[58] M. Armstrong-Stassen and A. Templer, "Adapting training for older employees: The Canadian response to an aging workforce," J. Manag. Dev., vol. 24, no. 1, pp. 57-67, 2005.

[59] T. J. Calo, "Talent Management in the Era of the Aging Workforce: The Critical Role of Knowledge Transfer," Public Pers. Manag., vol. 37, no. 4, pp. $403-$ 416, 2008.

[60] M. Shawn, M. Kim, and M. Jitendra, "Elderly workers in the workforce," Adv. Manag., vol. 7, no. 3, p. 1, 2014.

[61] D. C. Park, "Applied cognitive aging research.," in The handbook of aging and cognition., Hillsdale, NJ, US: Lawrence Erlbaum Associates, Inc, 1992, pp. 449-493.

[62] T. A. Salthouse, "When does age-related cognitive decline begin?," Neurobiol. Aging, vol. 30, no. 4, pp. 507-514, 2009.

[63] D. A. Balota, P. O. Dolan, and J. M. Duchek, "Memory changes in healthy older adults," Oxf. Handb. Mem., pp. 395-409, 2000.

[64] P. Verhaeghen, A. Marcoen, and L. Goossens, "Facts and fiction about memory aging: A quantitative integration of research findings," J. Gerontol., vol. 48, no. 4, pp. P157-P171, 1993.

[65] D. Head, K. M. Rodrigue, K. M. Kennedy, and N. Raz,
"Neuroanatomical and cognitive mediators of agerelated differences in episodic memory.,"

Neuropsychology, vol. 22, no. 4, p. 491, 2008.

[66] D. H. Schroeder and T. A. Salthouse, "Age-related effects on cognition between 20 and 50 years of age," Personal. Individ. Differ., vol. 36, no. 2, pp. 393-404, Jan. 2004.

[67] S. Umanath and E. J. Marsh, "Understanding How Prior Knowledge Influences Memory in Older Adults," Perspect. Psychol. Sci., vol. 9, no. 4, pp. 408-426, 2014.

[68] D. Kahneman and G. Klein, "Conditions for intuitive expertise: a failure to disagree.," Am. Psychol., vol. 64, no. 6, p. 515, 2009.

[69] J. E. Kubeck, N. D. Delp, T. K. Haslett, and M. A. McDaniel, "Does job-related training performance decline with age?," Psychol. Aging, vol. 11, no. 1, pp. 92-107, 1996.

[70] P. Brough, G. Johnson, S. Drummond, S. Pennisi, and C. Timms, "Comparisons of cognitive ability and job attitudes of older and younger workers," Equal. Divers. Incl. Int. J., vol. 30, no. 2, pp. 105-126, 2011.

[71] D. Dymock, S. Billett, H. Klieve, G. C. Johnson, and G. Martin, "Mature age 'white collar'workers' training and employability," Int. J. Lifelong Educ., vol. 31, no. 2, pp. 171-186, 2012.

[72] S. Franken, "Führen in der Arbeitswelt der Zukunft," Instrumente Tech. Best-Pract.-Beispiele Wiesb., 2016.

[73] K. R. Murphy, "Is the relationship between cognitive ability and job performance stable over time?," Hum. Perform., vol. 2, no. 3, pp. 183-200, 1989.

[74] S. Lass and N. Gronau, "Efficient Analysis of Production Processes with a Hybrid Simulation Environment," in Proceeding of the 22nd International Conference of Flexible Automation and Intelligent Manufacturing (FAIM 2012), Helsinki, Finnland, 2012.

[75] Kluge, A., Schüffler, A., Thim, C., Haase, J. and Gronau, N. (2019), "Investigating unlearning and forgetting in organizations", The Learning Organization, Vol. ahead-of-print No. ahead-ofprint. https://doi.org/10.1108/TLO-09-2018-0146

[76] J. D. Karpicke and H. L. Roediger, "The Critical Importance of Retrieval for Learning," Science, vol. 319, no. 5865, pp. 966-968, 2008.

[77] P. H. Hanel and K. C. Vione, "Do student samples provide an accurate estimate of the general public?," PloS One, vol. 11, no. 12, p. e0168354, 2016.

[78] J. Henrich, S. J. Heine, and A. Norenzayan, "The weirdest people in the world?," Behav. Brain Sci., vol. 33, no. 2-3, pp. 61-83, Jun. 2010. 